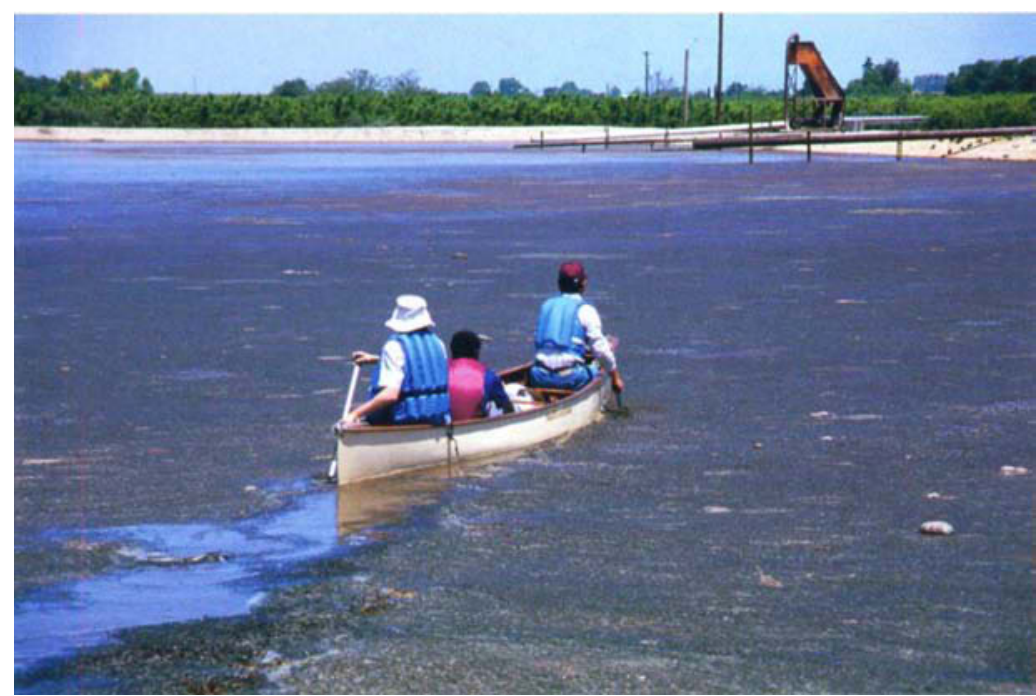

\section{Rapid test helps dairies manage wastewater}

$\mathrm{UC}$ scientists have developed a system for dairy operators to quickly measure nitrogen in dairy wastewater, giving them an important tool in the complex and environmentally sensitive task of managing wastewater lagoons.

Typically dairy wastewater is pumped from plastic-lined storage areas called lagoons or ponds onto adjacent farmland, where farmers grow corn or winter forage for cow feed. To ensure a good crop, commercial fertilizer is commonly added. But the practice can result in more nitrogen being applied than the crop can use. The

\section{Within 4 years, the nitrate level in shallow groundwater adjacent to the demonstration fields dropped nearly $75 \%$.}

A new method developed by UC scientists is helping dairies to better manage their wastewater lagoons. The researchers took measurements of a typical lagoon's oxygen and organic acid content.

compared to 24 milligrams per liter in shallow wells immediately upgradient of these dairies.

"Data seems to indicate that $80 \%$ of the nitrate associated with the groundwater is coming from misapplication of nutrients to the field,"

Campbell-Mathews says. "Fortunately, we can do something about that."

Campbell-Mathews says careful monitoring of nitrogen in dairy lagoon water and precise application procedures allow dairies to produce a topyielding crop and reduce the risk of contaminating groundwater. The scientists demonstrated the system at the Clauss Dairy Farm in Stanislaus County. Within 4 years, the nitrate level in shallow groundwater adjacent to the demonstration fields dropped nearly $75 \%$.

The research on groundwater contamination was conducted in a part of the state with sandy soils, which are more likely to allow nitrates to leach into groundwater.

"If we demonstrate significant improvements here in the worst-case scenario, we've developed a leftover can seep down into the aquifer and pollute groundwater.

"A lot of dairy operators don't have the capacity in a wet winter to hold all the water in their ponds," says Thomas Harter, UC Davis groundwater hydrologist. "It is standard practice to empty the pond in the fall. But if the soil is sandy, you can't put fertilizer on during one part of the year and hope it is there 6 months later to help plants grow."

Harter, UC Davis soils specialist Roland Meyer, UC Cooperative Extension farm advisor Marsha Campbell-Mathews and Regional Water Quality Control Board scientist Harley Davis reported in the Journal of Contaminant Hydrology this year that shallow groundwater in the vicinity of five Stanislaus County dairies had high levels of nitrate. Forty-four wells were installed at the five dairies and water quality was observed over a 4 -year period. The average shallow groundwater nitrate concentration was 64 milligrams per liter,

Campbell-Mathews worked with Hach Chemical to develop the 4- to 6-minute rapid ammonia test, which substitutes for a laboratory test that can take several days. Farmers can use the rapid test to sample lagoon water without ever leaving the lagoon bank.

Where the system has been implemented, farmers have been pleased with the results. "They are saving about $\$ 50$ to $\$ 70$ per acre on fertilizer costs and finding the nutrient management system is not any more hassle than hauling anhydrous ammonia tanks around the farm to apply fertilizer," Campbell-Mathews says.

The researchers have trained about 100 dairy operators on the new lagoon nutrient management system in Stanislaus, Fresno and Tulare counties, and developed a Web site for dairy farmers interested in implementing the system.

Go to: http:// groups.ucanr.org/lnm. - Jeannette Warnert 